\title{
Out-of-plane response of masonry infilled RC frames: Effect of workmanship and opening
}

\author{
F. Akhoundi, G. Vasconcelos, P. Lourenco \& L. Silva \\ University of Minho, Portugal
}

\begin{abstract}
Out-of-plane response of typical South European masonry infilled frames was investigated by testing three reduced scale specimens to investigate the effect of workmanship and presence of opening on the out-of-plane behaviour. The tests were performed considering an airbag to apply the uniform out-of-plane loading for each mass of the infill and by imposing pre-defined values of displacements in the out-of-plane direction in the control point taken at mid height and mid length of the masonry infill wall. Quasi-static cyclic testing was performed just in one direction to be able to monitor the propagation of the cracks and performance of the interfaces during out-of-plane loading. It was concluded that the workmanship is an important factor that may change the out-of-plane response of the specimen by changing the initial stiffness and lateral strength of the specimen. Another important contribution of the workmanship is the change of the collapse pattern of the infill by formation of twoway arching mechanism or one way arching mechanism. When the upper boundary condition of the infill in contact with RC frame is filled properly with mortar, two way arching mechanism was observed otherwise one-way horizontal arching mechanism was formed which exhibits lower out-of-plane resistance. The specimen with a central opening exhibits lower deformation capacity with respect to the reference wall but any decrease in its lateral strength was not recorded.
\end{abstract}

\section{INTRODUCTION}

Out-of-plane collapse of masonry infills within concrete frames has been observed in most of the earthquakes (Braga et al., 2011). Although the infill panels are assumed as non-structural elements, their damage or collapse is not desirable, given the consequences in terms of human life losses and repair or reconstruction costs. In addition, this type of damage can limit the immediate occupancy after the earthquake event. Aforementioned earthquakes such as L'Aquila earthquake (Braga et al., 2011), highlights the damages developed in the infill walls in relation to the minor cracks observed in the structure. In these cases, it was observed that no immediate occupancy was possible due to the generalized damage in the masonry infills. As it is observed in Figure 1 the ground motion was not strong enough to cause structural damage but due to improper anchorage and interaction of the infill walls and surrounding frame, the exterior walls damaged and fell outside and the concrete beam and columns were exposed.

Out-of-plane failure of the infills can be observed in dividing walls and also in multi-leaf walls when there is no proper transversal connection between the leaves as it is shown in Figure 2.

Studies on the out-of-plane behavior of masonry infilled RC frames can be found in literature
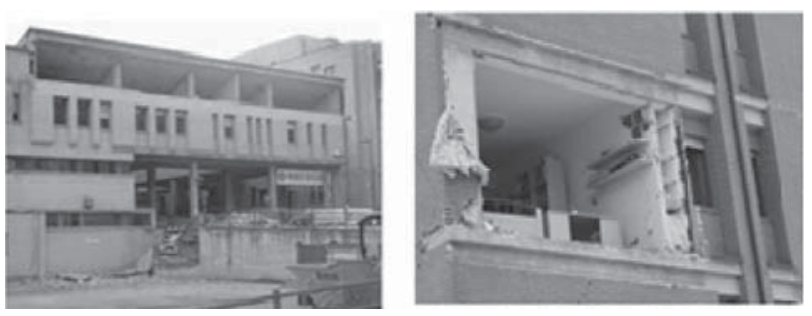

Figure 1. Damage in non-structural elements (Braga et al., 2011).
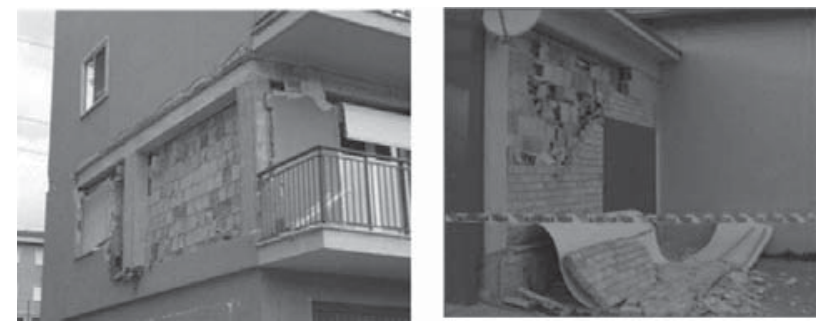

Figure 2. Detachment of the leaves in multi leaf walls (Braga et al., 2011).

(Dafnis et al., 2002, Dawe and Seah, 1989, Drysdale and Essawy, 1988, Tu et al., 2010, Flanagan and Bennett, 1999). From experimental analysis, it was observed that the masonry infill panel surrounded by RC or steel frame can resist significant out-of-plane loads due to formation of arching mechanism (Flanagan and Bennett, 1999). 
The experimental program of Dawe and Seah (Dawe and Seah, 1989) included 9 full scale masonry infilled steel frames that were subjected to uniformly distributed lateral pressure that was applied in small increments. Effect of boundary supports, joint reinforcement, panel thickness and presence of opening were investigated and it was concluded that infill compressive strength, panel dimension, boundary conditions and rigidity of the surrounding frame have significant effect on the ultimate load while presence of central opening (about $20 \%$ of infill area) do not affect the ultimate strength but reduces postcracking ductility.

A series of experiments were performed by Angel et al (Angel et al., 1994) focusing on the outof-plane strength of the panels. The panels varied from uncracked specimens, cracked specimens and repaired specimens, to specimens tested with loads applied in both the in-plane and the out-of-plane directions. The tests were performed monotonically by means of airbag in pressure control to a maximum allowable capacity of the system. It is concluded that the in-plane cracking reduces the out-of-plane capacity of the slender panels by a factor as high as 2 and the out-of-plane capacity of the panels are totally dependent on its slenderness ratio and compressive strength. It is also concluded that the repairing techniques increases the out-of-plane capacity of damaged infills by a factor as high as 5 .

The effect of different boundary conditions on the out-of-plane behavior of the infilled frames was investigated by different researchers (Dazio, 2008, Tu et al., 2010, Dafnis et al., 2002). Different connections conditions at the top interface between the infill and the frame were considered: (1) joint completely filled with mortar; (2) joint partially filled with mortar; (3) joint with horizontal gap of $3 \mathrm{~mm}$ due to shrinkage of the fresh mortar and (4) masonry infill with unsupported top. No significant differences in the behavior of the infills with complete and partially filled top joint have been found, whereas a $3 \mathrm{~mm}$ horizontal gap in the upper mortar joint caused a clearly modified behavior of the specimen. The presence of an initial gap in the top joints increases the relative displacement in the gap causing tilting of the infill panel. Infill panel with unsupported top behaved as cantilever beam. It was also concluded that the presence of opening does not alter specimen's dynamic behaviour. No local effects at the corners of the openings were investigated.

\section{MATERIAL AND METHODS}

\subsection{Test specimens}

Geometry and mechanical properties of the prototype of masonry infilled frames which are the typical of South European countries and described in this research were categorized in (Furtado et al., 2014). For the design of reduced scale specimens, an allowable stress design approach was followed. In the first step, sections of the columns and beams of prototype were analyzed based on ACI 318-08 guidelines to obtain the maximum allowable forces and flexural moments of each section. Then Cauchy's similitude law was applied to the allowable forces and flexural moments of real scale sections obtained in the first step to calculate the maximum allowable forces and flexural moments of reduced scale sections. In this step each mechanical or geometrical parameters of sections of the prototype was calculated based on Table 1. Finally, cross-section and reinforcement of the reduced scale sections were designed based on the same allowable stress design approach; see Figure 3 and Figure 4.

Three reduced-scale specimens were constructed in the scope of the test; namely SIF-A, SIF-B and PIF-B. The first section in the labelling process of the specimens relates to the presence of opening in the infill. "SIF" means that the infill is solid and there is no opening while "PIF" relates to partially infilled frame and means that there is opening inside infill. The second section in the labelling

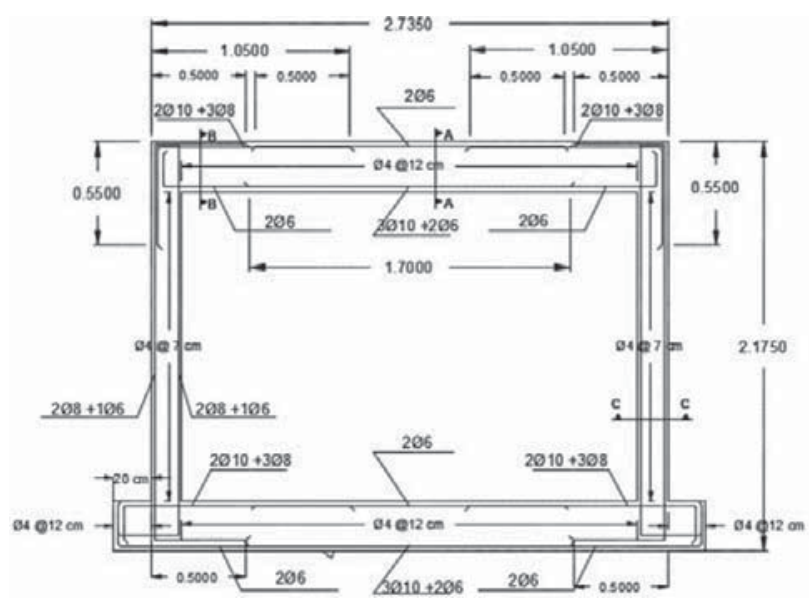

Figure 3. Geometry and reinforcement scheme of the reduced scale specimens.

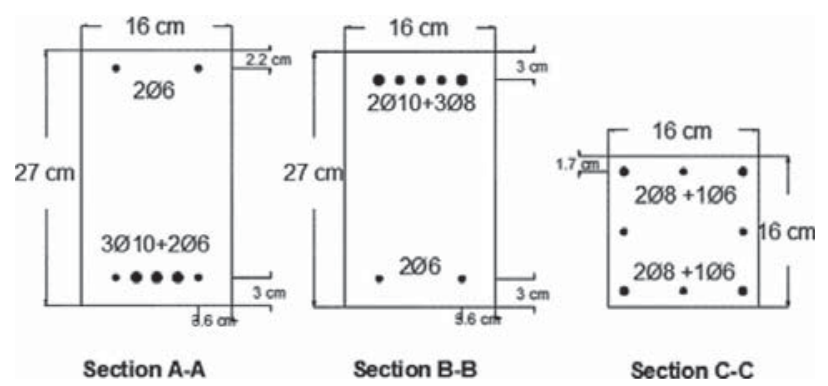

Figure 4. Cross-sections of columns and beams in reduced scale specimens. 
Table 1. Relation between different parameters of prototype and model in Cauchy's Similitude Law.

\begin{tabular}{|c|c|c|c|}
\hline Parameter & Scale factor & Parameter & Scale factor \\
\hline Length (L) & $\frac{L_{P}}{L_{m}}=\lambda$ & Mass (m) & $\frac{m_{P}}{m_{m}}=\lambda^{3}$ \\
\hline $\begin{array}{l}\text { Elasticity } \\
\text { Modulus } \\
\text { (E) }\end{array}$ & $\frac{E_{P}}{E_{m}}=1$ & Weight (W) & $\frac{W_{P}}{W_{m}}=\lambda^{3}$ \\
\hline $\begin{array}{l}\text { Specific } \\
\text { Mass }(\rho)\end{array}$ & $\frac{\rho_{P}}{\rho_{m}}=1$ & Force $(\mathrm{F})$ & $\frac{F_{P}}{F_{m}}=\lambda^{2}$ \\
\hline Area (A) & $\frac{A_{P}}{A_{m}}=\lambda^{2}$ & $\begin{array}{l}\text { Flexural } \\
\text { Moment } \\
\text { (M) }\end{array}$ & $\frac{M_{P}}{M_{m}}=\lambda^{3}$ \\
\hline Volume (V) & $\frac{V_{P}}{V_{m}}=\lambda^{3}$ & Stress $(\sigma)$ & $\frac{\sigma_{P}}{\sigma_{m}}=1$ \\
\hline $\begin{array}{l}\text { Displacement } \\
\text { (d) }\end{array}$ & $\frac{d_{P}}{d_{m}}=\lambda$ & Strain $(\varepsilon)$ & $\frac{\mathcal{E}_{P}}{\mathcal{E}_{m}}=1$ \\
\hline Velocity (v) & $\frac{v_{P}}{v_{m}}=1$ & Time $(\mathrm{t})$ & $\frac{t_{P}}{t_{m}}=\lambda$ \\
\hline $\begin{array}{l}\text { Acceleration } \\
\text { (a) }\end{array}$ & $\frac{a_{P}}{a_{m}}=\lambda^{-1}$ & $\begin{array}{l}\text { Frequency } \\
\text { (f) }\end{array}$ & $\frac{f_{P}}{f_{m}}=\lambda^{-1}$ \\
\hline
\end{tabular}

process relates to the group of mason that constructed the specimen. This means that the only difference between the specimens of SIF-A and SIF-B is in their workmanship.

The compressive strength of the masonry infill was determined as $1 \mathrm{MPa}$. This means that the masonry infill used in the frames can be considered as weak masonry infills. In the construction process of the specimens, the RC frame was constructed primarily and after passing its curing time, the construction of the infill was started by laying down the bricks in the horizontal direction. M5 Mortar was casted between the bricks in the horizontal and vertical joints and also between bricks and $\mathrm{RC}$ frame. This means that the masonry infill is in full contact with its surrounding frame.

The test setup for out-of-plane loading is shown in Figure 5 and Figure 6. As it is shown in Figure 5 , the infilled frame was placed on the same steel profiles of in-plane testing setup. All the test setup for out-of-plane testing is as same as the inplane test setup but the only difference is providing more out-of-plane resistance of the upper beam by putting four steel rods of M40 to prevent out-ofplane movement of the surrounding frame.

Out-of-plane loading is applied by means of airbag that is connected to its supporting frame.
Four rollers were mounted in the bottom part of the supporting frame to ease its moving along the direction of applied load. The supporting frame was also kept in touch with four loadcells to measure the load that is applied by airbag which their contact points are shown in Section A-A. The supporting frame of the loadcells was firmly connected to the strong floor and reaction wall to completely prevent its uplifting and sliding on the floor.

The instrumentation plan for the out-of-plane testing of solid infilled frame is shown in Figure 7 and for partially infilled frame is shown in Figure 8. In the specimen without opening, total number of fifteen LVDTs were mounted on the specimen to monitor its deformation while the out-of-plane load is applied. From them, nine LVDTs record the displacement history of the infill panel during loading (L1 to L9). Four LVDTs measure the relative displacement between infill and its surrounding frame (L10 to L13) and two LVDTs measure the out-of-plane movement of the upper and bottom reinforced concrete beam (L14 and L15).

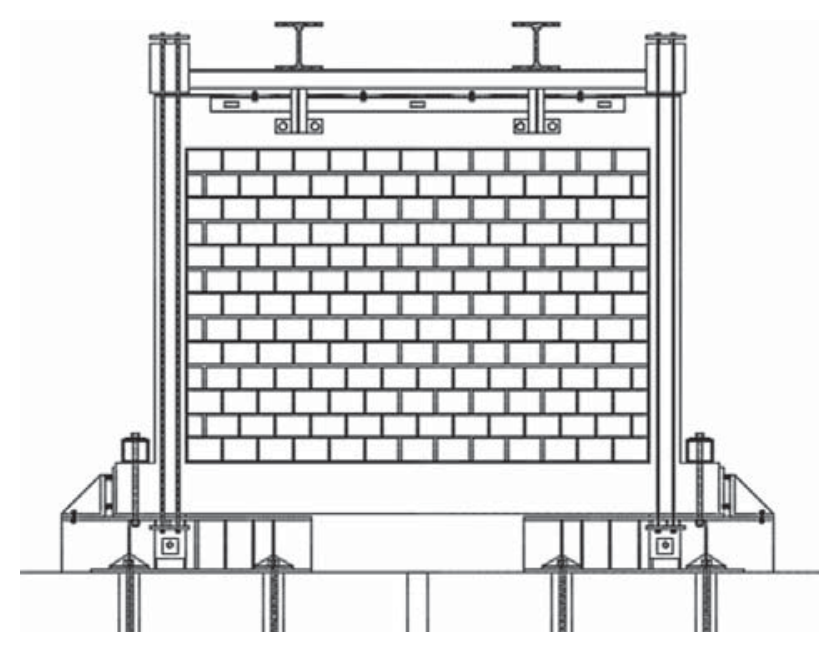

Figure 5. Test setup for out-of-plane testing.

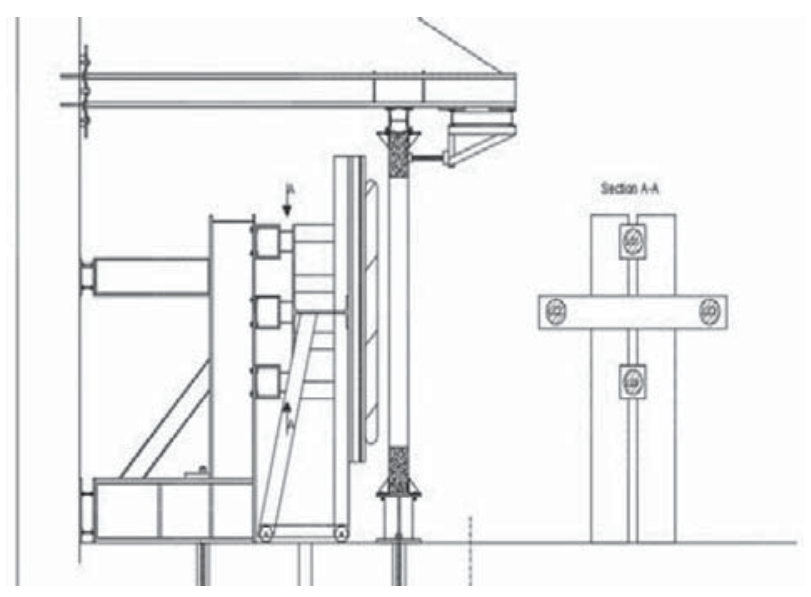

Figure 6. Test setup for out-of-plane testing. 


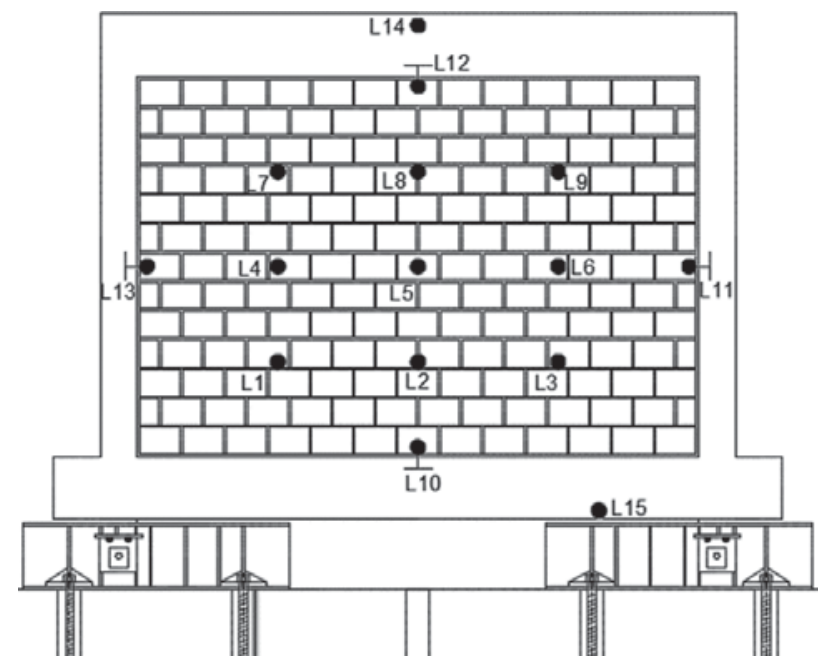

Figure 7. Instrumentation of the infilled frame without opening.

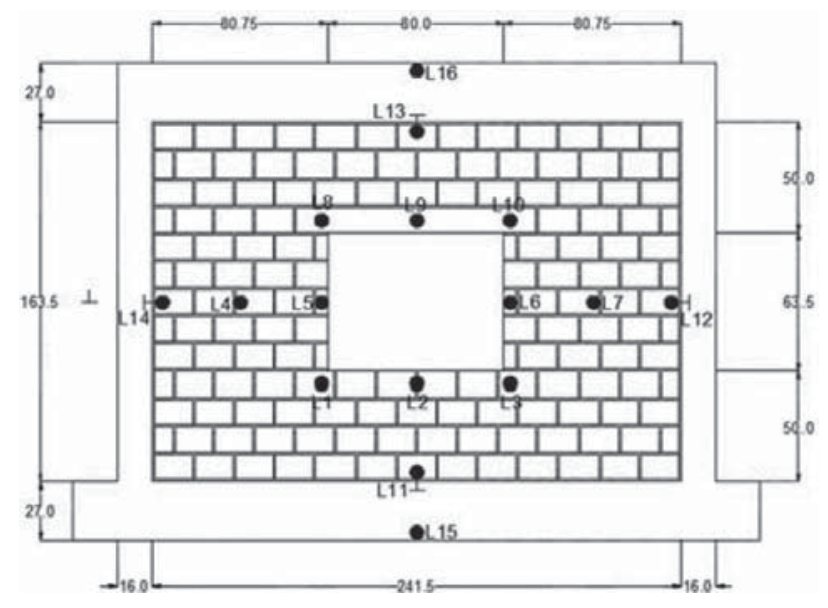

Figure 8. Geometry and instrumentation for specimen with central opening.

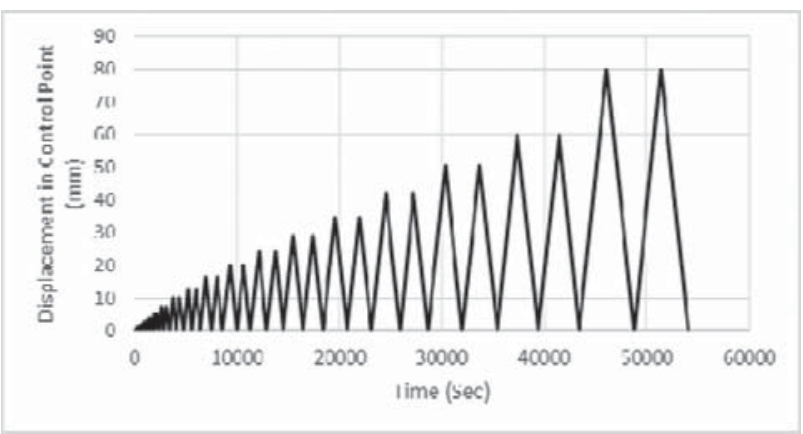

Figure 9. Loading protocol for out-of-plane testing.

Figure 9 shows the defined loading pattern for quasi-static cyclic testing of the specimens in the developed software for out-of-plane testing. It is composed of twenty different amplitudes applied for the control point of each specimen in which for solid infilled frame is assumed as central point (L5) and for partially infilled frame is assumed as central point of the infill in the upper part of opening (L9). The first amplitude repeated for six times and the others repeated two times to investigate the strength degradation of the specimen at each displacement. This loading protocol is compatible with FEMA461 (FEMA461, 2007). The loading was performed in one direction to monitor the deformation of the infill, propagation of the cracks and performance of the interfaces between infill and reinforced concrete frame during out-ofplane loading.

\section{RESULTS AND DISCUSSION}

\subsection{Specimen $S I F-A$}

Force-displacement diagram of the specimen is shown in Figure 10. It is observed that by applying lateral displacements up to $4 \mathrm{~mm}$ in the control point no cracks were formed in the specimen. The first cracking of the specimen was observed at lateral displacement of $5 \mathrm{~mm}$ corresponding to lateral force of $28.6 \mathrm{KN}$ by formation of horizontal cracks in the center part of the infill. After this point, initial stiffness of the specimen decreased significantly until it reaches the peak force of $34.9 \mathrm{KN}$ at lateral displacement of $25 \mathrm{~mm}$. After peak lateral force, by applying further displacement, sudden drop in lateral force was observed. $20 \%$ decrease in the maximum force was observed to reach the lateral force of $27.6 \mathrm{KN}$ corresponding to displacement of $28.1 \mathrm{~mm}$. Further displacement led to further decrease in the lateral force. The specimen was collapsed at lateral displacement of $50 \mathrm{~mm}$ corresponding to lateral force of 19.4 KN. Because the specimen collapsed at the first cycle of the amplitude of $50 \mathrm{~mm}$, the second cycle was not performed.

The monotonic curve of the force-displacement diagram at the first and second cycles of each step is shown in Figure 11. It seems that strength degradation of the specimen at two successive cycles is negligible until lateral displacement of $25 \mathrm{~mm}$ in

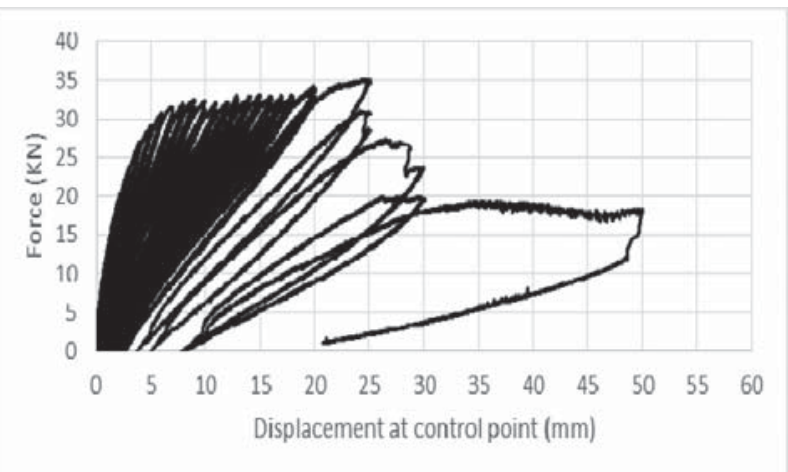

Figure 10. Hysteresis force-displacement diagram of SIF-A. 
which the upper interface moved in out-of-plane direction and the maximum force of $34.9 \mathrm{KN}$ was achieved. Strength degradation in the specimen could be considered as a contribution of the crack propagation. Because by increasing the number of cracks in the specimen, strength degradation increases. The degradation amount of $13 \%$ was observed at the peak point of the force-displacement diagram. At lateral displacement of $30 \mathrm{~mm}$ which infill was cracked totally, the strength degradation of $37 \%$ was observed.

Final cracking pattern of the specimen is drawn in Figure 12. It was observed that at the first levels of loading until displacement of $25 \mathrm{~mm}$ the two-way arching mechanism was formed in the specimen but at the second cycle of the amplitude $25 \mathrm{~mm}$, the upper interfaces cracked and bulged outside. This cracking of upper interface change the total cracking pattern of the specimen as shown in Figure 12. In this case, the cracking pattern of the specimen is compatible with the yield line theory of the slabs that have one free edge at their top part.

\subsection{Specimen $S I F-B$}

Force-displacement response of the specimen is shown in Figure 13. It is observed that at displacement of $3.76 \mathrm{~mm}$ the cracking in the infill was initiated by forming the horizontal cracks in the mid part of the infill. Significant decrease in the initial stiffness could be observed after displacement of $5.27 \mathrm{~mm}$ related to out-of-plane force of $30.9 \mathrm{KN}$ which could be related to the formation of diagonal step cracks. This means that by imposing higher displacement at the control point, force increases slowly until it reaches $39.7 \mathrm{KN}$ at displacement of $24.21 \mathrm{~mm}$. After the peak point, softening branch could be observed which increasing displacement leads to decrease in out-of-plane force to the extent that at displacement of $80 \mathrm{~mm}$ the residual strength of $22.4 \mathrm{KN}$ corresponding to $56 \%$ of the peak force

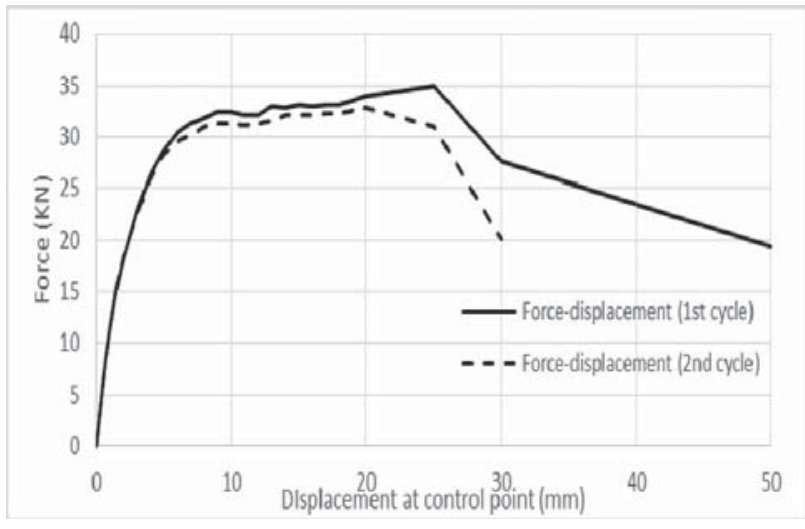

Figure 11. Monotonic force-displacement diagram of specimen SIF-A at each successive cycles.

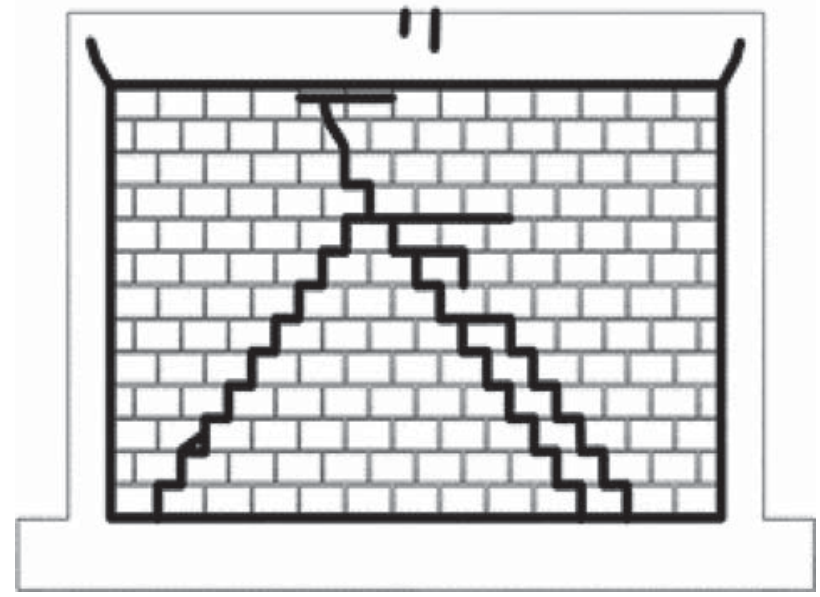

Figure 12. Failure pattern of the soecimen SIF-A.

was obtained. Because the specimen was collapsed at the first cycle of the amplitude of $80 \mathrm{~mm}$, the second cycle was not performed.

The monotonic curves of the force-displacement diagram for each cycle is shown in Figure 14. It is observed that by applying more displacements in the specimen which lead to the formation of more cracks, the amount of strength degradation increases. The increasing of the strength degradation in the specimen is assumed as insignificant because maximum amount of $10 \%$ was observed at lateral displacement of $60.5 \mathrm{~mm}$.

The final cracking pattern of the specimen is shown in Figure 15. In this specimen the cracking pattern is compatible with the yield line theory of the slabs that have four supports. In this case, in the first stages of loading a horizontal crack initiated at the mid-part of the specimen and by applying further displacements to the control point, some diagonal cracks formed at the end part of the horizontal crack trying to reach the corners of the infill. The failure pattern of the specimen exhibits that the two-way arching mechanism that was formed in the initial stages of the test, remained unchanged until the end of the test.

\subsection{Specimen PIF-B}

Force-displacement diagram of the specimen at control point is shown in Figure 16. It is observed that the first cracking initiated at displacement of $3.76 \mathrm{~mm}$ corresponding to the out-of-plane force of $26.6 \mathrm{KN}$. Nonlinearity in the force-displacement diagram was observed before observing the cracks in the specimen. By applying further displacement to the control point, the out-of-plane force was increased until it reached to $39 \mathrm{KN}$ at displacement of $12.91 \mathrm{~mm}$. After this point, increasing the displacement in control point resulted in small decrease in out-of-plane force. Finally the specimen was collapsed at displacement of $24.46 \mathrm{~mm}$ corre- 


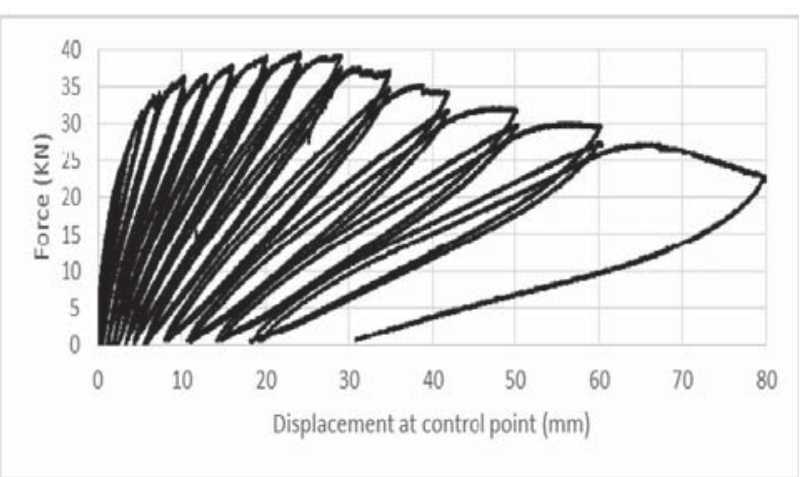

Figure 13. Hysteresis force-displacement diagram of SIF-B.

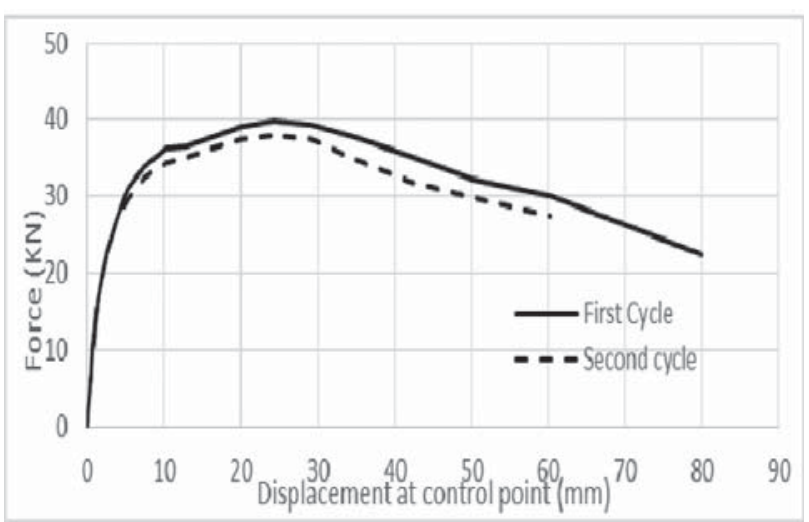

Figure 14. Monotonic force-displacement diagram of specimen SIF-B at each successive cycles.

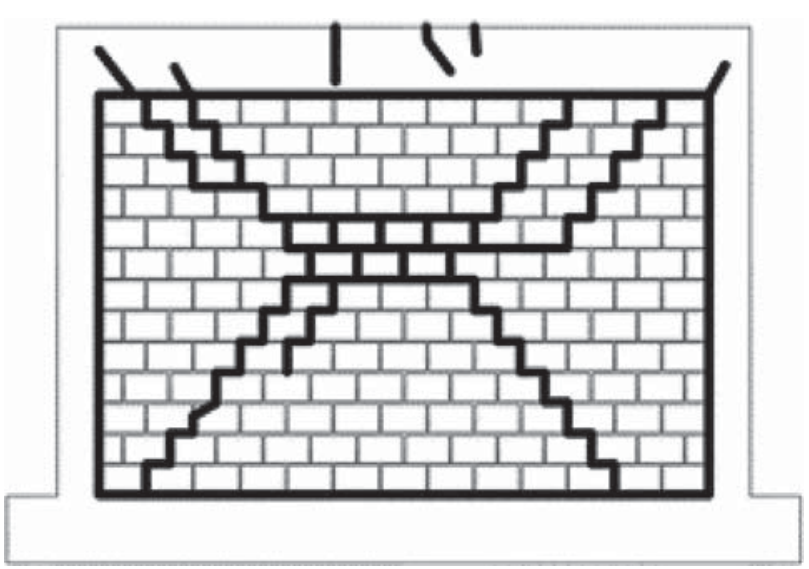

Figure 15. Failure pattern of the soecimen SIF-B.

sponding to the force of $31.1 \mathrm{KN}$ by out-of-plane failure of the right side of the opening in the infill. Right part of the infill experienced more damage with respect to the other parts of the infill. This could be related to the position of the valves of input air in the airbag that were placed in its right side. It seems that this issue have led to asymmetric loading of the infill.
The monotonic force-displacement diagram for each successive cycles are shown in Figure 17. It is observed that strength degradation in the specimen starts by formation of cracks in the specimen which is similar with the other tests. The maximum strength degradation of $12 \%$ was happened at lateral displacement of $12.91 \mathrm{~mm}$ corresponding to the peak load of $39 \mathrm{KN}$ while for other displacements the amount of strength degradation is less than $10 \%$.

The final cracking pattern of the specimen is shown in Figure 18. It is observed that the cracking of the specimen initiated at the corners of the opening by formation of some diagonal cracks trying to reach the corners of the infill. Increasing the displacement at the control point lead to formation of some horizontal crack in the top part of the infill and finally the specimen failed as shown in Figure 18. It seems that the two-way arching mechanism is also formed in this specimen to resist the out-of-plane loading and remained unchanged until the failure of the specimen.

\subsection{Discussion}

The force-displacement diagram of the specimens are shown in Figure 19. It is clear that the forcedisplacement diagram of the specimen constructed with group of mason " $\mathrm{A}$ " is totally different with experience group of mason " $\mathrm{B}$ ". The parameters related to the out-of-plane behaviour of the specimens namely initial stiffness measured as the slope of the force-displacement diagram at 30\% of maximum force and the out-of-plane resistance of the specimens are represented in Table 2. It seems that the boundary conditions of the specimen totally affect the out-of-plane behaviour of the specimen. Workmanship as observed in the test results of SIF-A could affect those boundary conditions. It is clear that in the specimen SIF-A, the upper interface lost its functionality due to

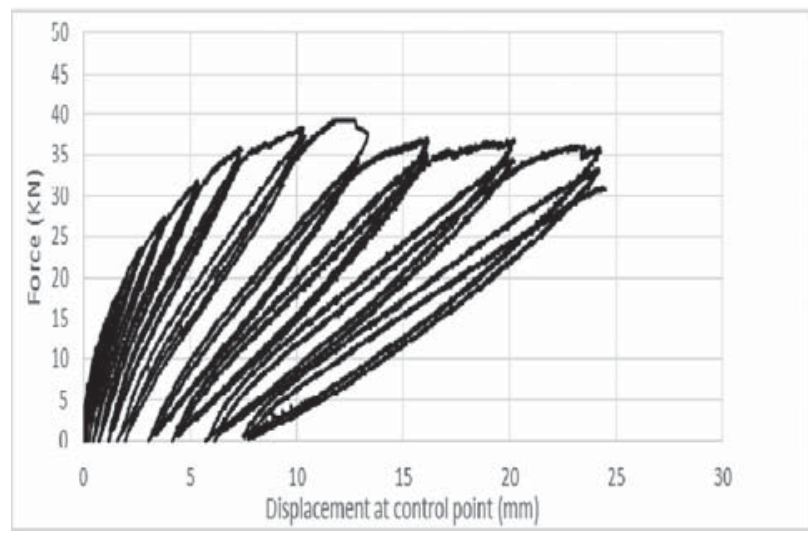

Figure 16. Hysteresis force-displacement diagram of PIF-B. 


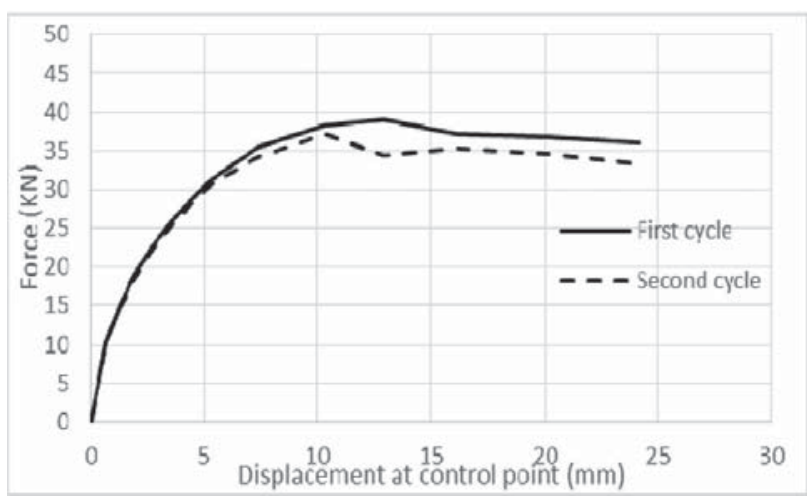

Figure 17. Monotonic force-displacement diagram of specimen PIF-B at each successive cycles.

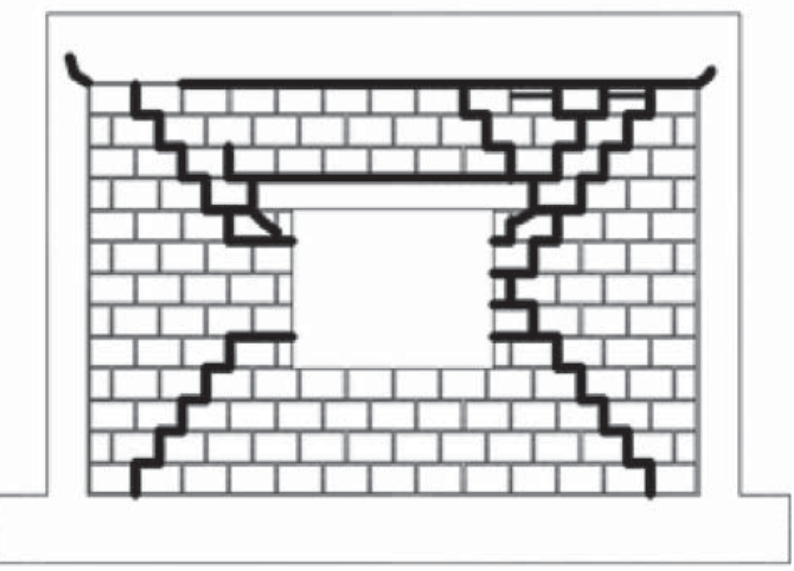

Figure 18. Failure pattern of the soecimen PIF-B.

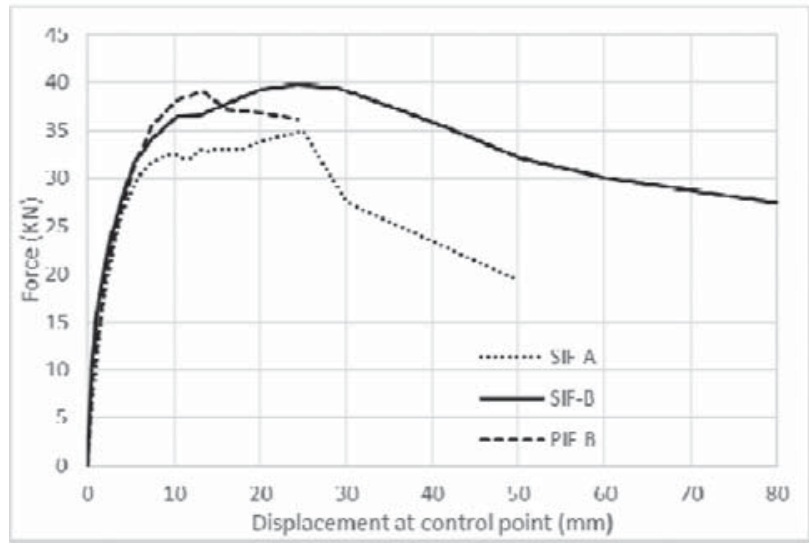

Figure 19. Force-displacement diagram of the specimen.

Table 2. Parameters related to the out-of-plane behavior of specimens.

\begin{tabular}{lll}
\hline Specimen & $\begin{array}{l}\text { Initial stiffness } \\
(\mathrm{KN} / \mathrm{mm})\end{array}$ & $\begin{array}{l}\text { Maximum } \\
\text { force }(\mathrm{KN})\end{array}$ \\
\hline SIF-A & 11.5 & 34.9 \\
SIF-B & 18.2 & 39.8 \\
PIF-B & 16.0 & 39.0 \\
\hline
\end{tabular}

improper filling of the mortar joints adjacent to the upper RC beam and slided in the out-of-plane direction. This was resulted in lower out-of-plane resistance of the specimen by changing its boundary conditions.

It can be easily concluded that the specimen constructed with experienced mason (group "B") exhibits higher initial stiffness and out-of-plane resistance. The increase in the initial stiffness and maximum force are calculated as $58 \%$ and $14 \%$ respectively.

It is also concluded that presence of small central opening (13\% area of infill) did not result in decrease of the out-of-plane resistance of the specimen while $12 \%$ decrease in the initial stiffness was observed. Based on Figure 19 and comparing the force-displacement diagram of the specimens SIF-B and PIF-B, it could observed that presence of even small percentage of opening in the infill results in decrease in the deformation capacity of the specimen while it does not lead to any significant decrease in the lateral strength of the specimen.

\section{CONCLUSIONS}

Laboratory testing was conducted on three reduced scale infilled frame representing the typology of South European countries and the following conclusion were made;

- Workmanship could significantly affect the outof-plane behaviour of the specimen by disturbing their boundary conditions. The increase in the initial stiffness and maximum force in the specimen constructed with experienced mason was reported as $58 \%$ and $14 \%$ respectively. In the specimen constructed with mason type "A" the upper interface lost its functionality due to improper filling of the mortar joints adjacent to the upper RC beam and slided in the out-ofplane direction.

- Presence of even small percentage of opening inside infill results in significant decrease in the deformation capacity of the specimens. It is observed that the specimen with central opening collapsed at low displacement applied in its control point. The maximum deformation in the control point of the specimen with central opening is $1 / 4$ of the displacement in which the solid specimen collapsed at.

- It is also concluded that presence of opening inside infill resulted in the reduction of initial stiffness. Presence of opening with 13\% area of the infill resulted in $12 \%$ decrease in the initial stiffness while no change in the load bearing capacity of the specimen was observed. 


\section{ACKNOWLEDGEMENTS}

The authors acknowledge Portuguese Foundation of Science and Technology for the funding of the project RetroInf-Development of innovative solutions for seismic retrofitting of masonry infill walls (PTDC/ECM/122347/2010).

This work was also supported by FCT (Portuguese Foundation for Science and Technology), within ISISE, project UID/ECI/04029/2013.

\section{REFERENCES}

Angel, R., Abrams, D., Shapiro, D., Uzarski, J. \& Webster, M. (1994) Behaviour of reinforced concrete frames with masonry infills. Urbana-Champaign, IL, USA.

Braga, F., Manfredi, V., Masi, A., Salvatori, A. \& Vona, M. (2011) Performance of non-structural elements in RC buildings during the L'Aquila, 2009 earthquake. Bulletin of Earthquake Engineering, 9, 307-324.

Dafnis, A., Kolsch, H. \& Reimerdes, H. (2002) Arching in Masonry Walls Subjected to Earthquake Motions. Journal of Structural Engineering, 128, 153-159.
Dawe, J.L. \& Seah, C.K. (1989) Out-of-plane resistance of concrete masonry infilled panels. Canadian Journal of Civil Engineering, 16, 854-864.

Dazio, A. (2008) Effect of boundary conditions on the out-of-plane behavior of unreinforced masonry walls. 14th World Conference on Earthquake Engineering. Beijing, China.

Drysdale, R. \& Essawy, A. (1988) Out-of-Plane Bending of Concrete Block Walls. Journal of Structural Engineering, 114, 121-133.

FEMA461 (2007) Interim Testing Protocols for Determining the Seismic Performance Characteristics of Structural and Nonstructural Components.

Flanagan, R. \& Bennett, R. (1999) Bidirectional Behavior of Structural Clay Tile Infilled Frames. Journal of Structural Engineering, 125, 236-244.

Furtado, A., Costa, C., Rodrigues, H. \& Arêde, A. (2014) Characterization of structural characteristics of Portuguese buildings with masonry infill walls stock. 9th International Masonry Conference. University of Minho, Guimarães, Portugal.

Tu, Y.H., Chuang, T.H., Liu, P.M. \& Yang, Y.S. (2010) Out-of-plane shaking table tests on unreinforced masonry panels in RC frames. Engineering Structures, $32,3925-3935$ 